\title{
Welcome to a new volume of Lab Animal!
}

Now in our 42nd year, Lab Animal is still the premier source of information, ideas, methods and materials for the animal research professional. This year, we're proud to announce that we're bigger and brighter, with brand-new contents expanding our editorial coverage of key subjects in lab animal science. Here is a brief introduction to our new columns and features.

\section{COLUMNS}

You'll find these new columns in each issue of Lab Animal this year:

In Fruits of Education, Column Coordinator Bruce W. Kennedy, MS, RLATG, CMAR, CPIA will address training topics that pertain to animal care and use.

Outreach, contributed by Paul McKellips of the Foundation for Biomedical Research, will inspire the research community by advocating its essential role in medical progress.

Website Reviews will assess online resources for animal research information, alternating every month with Book Reviews, which evaluate print resources.

\section{FEATURES}

Features will appear regularly, though not in every issue. Check the first page of the Table of Contents each month to see these highlighted:

Case Reports will describe noteworthy veterinary medical findings in a classic casediagnosis format.

Policy Watch, contributed by the National Association for Biomedical Research, will cover regulatory and policy matters.
News Features will offer in-depth reporting on research-related news.

Policy Watch, Website Review, Case Report, Fruits of Education and Outreach all make their first appearances in this issue.

The new items join the popular Model of the Month column and Meeting Report feature that we introduced in 2012. Last year also brought the expansion of our Newsfronts section and frequency increases for the Careers \& Recruitment and Book Review columns. It's an exciting time of growth for Lab Animal, and we're glad you're here to experience it with us. Look for your subscription reminder soon, and renew your subscription for 2013 to stay up-to-date with all of our new contents.

This year also marks the debut of the totally redesigned Lab Animal Buyers' Guide. The Guide you've always counted on for reliable product listings is better than ever. Featurerich and user-friendly, the new Buyers' Guide is launching soon at http://guide.labanimal.com/. Don't miss it!

We truly hope you will enjoy our new material. Tell us what you think by submitting your ideas, feedback and suggestions by email to editors@labanimal.com.

\section{Monica Harrington} Editor, Lab Animal 